www.jmscr.igmpublication.org

Impact Factor (SJIF): 6.379

Index Copernicus Value: 71.58

ISSN (e)-2347-176x ISSN (p) 2455-0450

crossref DOI: _https://dx.doi.org/10.18535/jmscr/v6i4.68

Journal Of Medical Science And Clinical Research

IGM Publication

An official Publication of IGM Publication

\title{
Study of comparative effect of hydroxychloroquine and vildagliptin on glycaemic efficacy and HbA1cin type 2 diabetes patients who were inadequately controlled with metformin and glimepiride dual therapy
}

\author{
Authors
}

\section{Dr Arjun Baidya ${ }^{1}$, Dr Manish Kumar², Dr Shailesh Kumar Pathak, Dr Rishad Ahmed ${ }^{4}$}

${ }^{1}$ Department of Endocrinology, Nil Ratan Sircar Medical College \& Hospital, Kolkata, West Bengal, India

${ }^{2}$ Department of Medicine, Patna Medical College \& Hospital, Patna, Bihar, India

${ }^{3}$ Department of Medicine, Patna Medical College \& Hospital, Patna, Bihar, India

${ }^{4}$ Department of Medicine, KPC Medical College, Kolkata, West Bengal, India

Corresponding Author

\section{Arjun Baidya}

Department of Endocrinology, Nil Ratan Sircar Medical College and Hospital, 138, AJC Bose Road,

Kolkata, West Bengal 700014, India

Email: arjun.baidya@gmail.com

\begin{abstract}
Objective: The objective of this study is investigate the glycaemic efficacy parameters of hydroxychloroquine (HCQ) in comparison to those of vildagliptin in uncontrolled type 2 diabetes mellitus (T2DM) patients who were inadequately controlled with metformin and glimepiride dual therapy.

Methods: Uncontrolled type 2 diabetes patients with glycated haemoglobin (HbAlc) of 7.0-9.0\% and on metformin up to $1000 \mathrm{mg} /$ day along with glimepiride up to $2 \mathrm{mg} /$ day were selected for the study. Hundred eligible patients were randomly divided into two groups. One group comprises of 50 patients whose baseline fasting plasma glucose (FPG), post prandial plasma glucose (PPPG), HbAlc were determined and the patients were put on hydroxychloroquine $400 \mathrm{mg}$ per day apart from metformin $1 \mathrm{gm} /$ day and glimepiride $2 \mathrm{mg} /$ day, another group comprises of 50 patients whose baseline FPG, PPPG, HbAlc were determined and put on vildagliptin $100 \mathrm{mg}$ per day apart from metformin $1 \mathrm{gm} /$ day and glimepiride $2 \mathrm{mg} /$ day. At 3 months and 6 months, levels of glycaemic parameters were compared with those at baseline.

Results: At 3 months, while similar reductions of glycated hemoglobin (HbAlc) levels were observed with these two drugs, after 24 weeks of treatment with hydroxychloroquine 400mg, metformin and glimepiride, subjects had greater reduction in FPG, PPPG and HbAlc as compared to vildagliptin, glimepiride and metformin.

Conclusion: This study showed that hydroxychloroquine can be an effective alternative to DPP4 inhibitors like vildagliptin for add on therapy to the patients who are inadequately controlled with metformin and glimepiride dual therapy.
\end{abstract}

Keywords: Glycemic efficacy, HbAlc, Hydroxychloroquine, Type2 diabetes, Vildagliptin.

\section{Introduction}

T2DM is a long term metabolic disorder that is characterized by high blood glucose, insulin resistance, and relative lack of insulin. It is due to insufficient insulin production from beta cells in the setting of insulin resistance ${ }^{1}$. Insulin 
resistance, which is the inability of cells to respond adequately to normal levels of insulin, occurs primarily within the muscles, liver, and adipose tissue. In the liver, insulin normally suppresses glucose release ${ }^{2}$. The prevalence of T2DM is increasing all over the world, especially in South Asia. India has second largest population of diabetic patients. The International Diabetes Federation (IDF) estimates the number of people with diabetes in India will reach 80 million by the year $2025^{3}$.

There are at least seven different classes of agents used as monotherapy, or in combinations for the treatment of diabetes mellitus. Treatment include metformin, sulphonylureas, miglitinides, alphaglucosidase inhibitors, thiazolidinediones (TZD), DPP-4 inhibitors and insulin. Many conventional agents frequently exhibit reduced efficacy over time, leading to inadequate glycaemic control.

Dipeptidyl peptidase 4 (DPP-4) inhibitor is a relatively new class of antihyperglycemic agents that are now recommended as first or second-line agents in treatment of diabetes by guidelines like American Diabetes Association (ADA) 2016 and

American Association of Clinical Endocrinologists and American College of Endocrinology 2016. DPP-4 inhibitors control fasting plasma glucose (FPG) and postprandial plasma glucose (PPPG) levels through selective inhibition of DPP-4, resulting in increased plasma concentrations of active glucagon-like peptide1.

Hydroxychloroquine has shown its beneficial effects in various cardiovascular risks, particularly diabetes and dyslipidemia ${ }^{4}$. Recently, it has been reported that hydroxychloroquine reduce both glucose and lipid levels in people with diabetes and one report of hypoglycemic coma in individual with type 2 diabetes who was prescribed hydroxychloroquine ${ }^{5}$.

Hydroxychloroquine showed improved glycaemic control in a cross-sectional study of cardiovascular disease risk factors in women with systemic lupus erythematous or rheumatoid arthritis and in sulfonylureas refractory patients. An observational study of 4905 rheumatoid arthritis patients showed a reduced risk of developing diabetes in patients with hydroxychloroquine use compared to those who never used hydroxychloroquine ${ }^{6}$.

Although all the oral antidiabetic agents are reasonably effective as monotherapy in improving glycaemic control but due to progressive nature of type $2 \mathrm{DM}$, monotherapy is often associated with inadequate control of glycaemia and loss of efficacy over time ${ }^{7}$. Combining agents with different modes of action produce additive effects on glycaemic control, allows the use of submaximal doses of the agents, thereby decreasing the unwanted side effects and have complementary benefits on cardiovascular risk factors ${ }^{8}$. Therefore the need of adding second oral antihyperglycemic agent is required when metformin or sulfonylureas do not achieve HbA1c target or metformin monotherapy at maximal tolerated dose over 3 to 6 months.

Therefore, the present study was designed tostudy the comparative effect of vildagliptin and hydroxychloroquine on glycaemic efficacy parameters in type 2 diabetes patients who were inadequately controlled with metformin and glimepiride dual therapy.

\section{Material and Methods}

The study was a prospective, parallel-group, openlabel, active controlled, randomized study conducted from October, 2017 to March, 2018 (6 months). This study was a multi centric study. Uncontrolled type 2 diabetes patients with glycated haemoglobin (HbA1c) of 7.0-9.0\% and on metformin up to $1000 \mathrm{mg} /$ day along with glimepiride up to $2 \mathrm{mg} /$ day were selected for the study. Initially 160 known T2DM patients were screened, out of which only 100 uncontrolled T2DM patients were eligible as per the criteria which has fixed prior to the study. Selected patients were randomly divided into two groups. One group comprises of 50 patients whose baseline FPG, PPPG, HbA1c were determined and the patients were put on hydroxychloroquine 400 $\mathrm{mg}$ per day apart from metformin $1 \mathrm{gm} /$ day and glimepiride $2 \mathrm{mg}$ /day, another group comprises of 
50 patients whose baseline FPG, PPPG, HbA1c were determined and put on vildagliptin $100 \mathrm{mg}$ per day apart from metformin $1 \mathrm{gm} /$ day and glimepiride $2 \mathrm{mg}$ /day. With a proper diabetic diet counselling, patients were monitored closely. At 3 months and 6 months, levels of glycaemic parameters were compared with those at baseline.

Inclusion Criteria: Patients diagnosed of type 2 diabetes who are receiving treatment with metformin $1000 \mathrm{mg}$ /day and glimepiride $2 \mathrm{mg} /$ day are on stable dose for at least 12 weeks. Patients with $\mathrm{HbA} 1 \mathrm{c} \geq 7.0 \%$ and $\leq 9 \%$. Patients with body weight $\geq 60 \mathrm{~kg}$. Patients able to understand and willing to fully comply with study procedures and restrictions.

After informed consent was obtained, patients were prescribed to receive the hydroxychloroquine $400 \mathrm{mg}$, glimepiride $2 \mathrm{mg}$, and metformin $1000 \mathrm{mg}$ daily for six months.

Exclusion Criteria: FPG $>240 \mathrm{mg} / \mathrm{dL}$. Patients with a history or presence of any retinopathy of any grade including diabetic retinopathy requiring laser therapy, evidence of an imminent need for retinal laser therapy, uncorrected visual acuity $<20 / 100$, abnormal visual fields, difficulty to examine optic disc, or evidence of retinal pigment epithelial abnormalities and patients with history or risk of macular edema. Patients with recent $(<1$ year) cardiovascular events i.e. myocardial infarction or acute coronary syndrome, stroke or has undergone coronary artery bypass surgery, percutaneous transluminal coronary angioplasty or transient ischemic attack, or history of congestive heart failure, or unstable angina. Patient with known history of diabetic ketoacidosis, glucose-6phosphate dehydrogenase deficiency, known allergy to the substance, pregnancy and breastfeeding.

Efficacy and safety evaluation: The primary objective was glucose triad (HbA1c, fasting glucose and post-prandial glucose level) change from baseline to 6 months after treatment. Secondary objectives were percentage of patients achieving HbA1c $<6 \%$, change of serum creatinine and SGPT levels.
Statistical methods: Statistical analysis was done by using SPSS version 17.0. Descriptive statistics were used for categorical variables. The efficacy of combination therapy was assessed by Paired $t$ test. In order to study the efficacy of combination therapy Paired $t$ test was performed after completion of 12 weeks and 24 weeks of therapy.

\section{Results}

\section{Baseline characteristics of the study subjects}

The demographics and clinical characteristics of the randomized subjects are summarized in Table 1. $60 \%$ of the subjects were female in hydroxychloroquine combination group and 58\% were of vildagliptin combination group. The mean age was 58.36 years HCQ group and 56.24 years in vildagliptin group.

Body mass index (BMI) of patients indicates that majority of the patients were in the overweight range $(25-29.9 \mathrm{~kg} / \mathrm{m} 2)$ in both the groups. No obvious change in the BMI was observed after 6 months of treatment in both the group.

Table 1: Baseline characteristics of the study subjects

\begin{tabular}{|l|c|c|}
\hline Characteristics & $\begin{array}{c}\text { HCQ+Met+SU } \\
\mathbf{N = 5 0}\end{array}$ & $\begin{array}{c}\text { Vilda+Met+SU } \\
\mathbf{N = 5 0}\end{array}$ \\
\hline Age (yrs) & $58.36 \pm 8.59$ & $56.24 \pm 7.40$ \\
\hline Gender \% (Female) & $60 \%$ & $58 \%$ \\
\hline Body weights (kg) & $83.16 \pm 11.46$ & $82.61 \pm 10.87$ \\
\hline BMI (kg/m2) & $26.97 \pm 5.2$ & $26.27 \pm 4.9$ \\
\hline Duration of diabetes (yrs) & $10.23 \pm 6.27$ & $10.19 \pm 6.18$ \\
\hline Serum Creatinine & $0.83 \pm 0.34$ & $0.82 \pm 0.31$ \\
\hline SGPT & $28.68 \pm 5.59$ & $28.36 \pm 5.32$ \\
\hline FPG (mg/dl) & $149.6 \pm 28.4$ & $150.43 \pm 19.8$ \\
\hline PPPG (mg/dl) & $240.4 \pm 44.4$ & $241.3 \pm 38.5$ \\
\hline Mean HbAlc level (SD), \% & $7.8 \pm 0.9$ & $7.9 \pm 0.8$ \\
\hline
\end{tabular}

\section{Change of HbA1c, FPG and PPPG}

The primary endpoint of the study was to monitor the changes in HbA1c levels, FPG, PPPG, from baseline to week 12 and week 24. (Table 2)

It was observed that the mean FPG $(109.36 \mathrm{mg} / \mathrm{dl}$ \pm 18.4)at 24 weeks after addition of hydroxychloroquine $400 \mathrm{mg}$ was less as compared to addition of vildagliptin $100 \mathrm{mg}(120.56 \mathrm{mg} / \mathrm{dl}$ \pm 18.4 ) (p value $<0.0001$ ) group (Table 2 ). 
Similarly mean PPPG (151.36 mg/dl \pm 18.8$)$ at 24 weeks after addition of hydroxychloroquine 400 $\mathrm{mg}$ was less as compared to addition of vildagliptin $100 \mathrm{mg}(167.36 \mathrm{mg} / \mathrm{dl} \pm 19.4)$ (p value $<0.0001)$ group(Table 2).

At week 24, the mean $\mathrm{HbA1c}$ decreased from $7.8 \pm 0.9$ to $6.5 \pm 0.9$ in hydroxychloroquine group and from $7.9 \pm 0.8$ to $6.8 \pm 0.9$ in vildagliptin group, respectively. There was over all $1.3 \%$ reduction of HbA1c from baseline in HCQ group, where as in vildagliptin group it was only $1.1 \%$ (Table 3).Only 2 patients in HCQ group complains for mild hypoglycemia whereas on vildagliptin arms 5 patients has suffered from such incidence. No patients taking HCQ or Vildagliptin required medical assistance for severe symptomatic hypoglycemia. There were only mild/transient adverse effects in the patients, with no drop outs due to an adverse reaction. No deaths were reported during the study.

Table 2: Change of HbA1c, FPG and PPPG

\begin{tabular}{|c|c|c|c|c|c|c|c|c|}
\hline \multirow{2}{*}{ Characteristics } & \multicolumn{4}{|c|}{$\begin{array}{c}\mathrm{HCQ}+\mathrm{Met}+\mathrm{SU} \\
\mathbf{N}=\mathbf{5 0}\end{array}$} & \multicolumn{4}{|c|}{$\begin{array}{c}\text { Vilda }+ \text { Met }+ \text { SU } \\
\mathbf{N}=\mathbf{5 0}\end{array}$} \\
\hline & $\begin{array}{c}\text { Baselin } \\
\text { e }\end{array}$ & $\begin{array}{c}\text { 3rd } \\
\text { Month }\end{array}$ & $\begin{array}{c}\text { 6th } \\
\text { Month }\end{array}$ & $\mathbf{P}$ & $\begin{array}{l}\text { Basel } \\
\text { ine }\end{array}$ & $\begin{array}{c}\text { 3rd } \\
\text { Month }\end{array}$ & $\begin{array}{c}\text { 6th } \\
\text { Month }\end{array}$ & $\mathbf{P}$ \\
\hline $\begin{array}{l}\text { Mean HbA1c } \\
\text { level (SD), \% }\end{array}$ & $\begin{array}{r}7.8 \\
\pm 0.9\end{array}$ & $6.9 \pm 0.4$ & $\begin{array}{c}6.5 \\
\pm 0.9\end{array}$ & $<0.0001$ & $\begin{array}{l}7.9 \\
\pm 0.8\end{array}$ & $\begin{array}{c}7.1 \pm 0.4 \\
3\end{array}$ & $\begin{array}{c}6.8 \\
\pm 0.9\end{array}$ & $<0.0001$ \\
\hline FPG (mg/dl) & $\begin{array}{l}149.6 \\
\pm 28.4 \\
\end{array}$ & $\begin{array}{c}128.3 \pm \\
21.3\end{array}$ & $\begin{array}{l}109.36 \\
\pm 18.4\end{array}$ & $<0.0001$ & $\begin{array}{l}150.4 \\
\pm 19.8\end{array}$ & $\begin{array}{c}130.3 \pm 2 \\
2.5\end{array}$ & $\begin{array}{l}120.56 \\
\pm 18.4\end{array}$ & $<0.0001$ \\
\hline PPPG (mg/dl) & $\begin{array}{l}240.4 \\
\pm 44.4\end{array}$ & $\begin{array}{l}196.39 \\
\pm 28.30\end{array}$ & $\begin{array}{r}151.36 \\
\pm 18.80\end{array}$ & $<0.0001$ & $\begin{array}{l}241.3 \\
\pm 38.5\end{array}$ & $\begin{array}{c}201.57 \pm \\
24.26\end{array}$ & $\begin{array}{l}167.36 \\
\pm 19.40\end{array}$ & $<0.0001$ \\
\hline
\end{tabular}

Note: Values presented as mean (SD), and compared using two sample t test. Least square mean change from baseline (95\% CI) adjusted to its baseline value. Comparison with baseline using paired $t$ test. HbAlc - glycosylated hemoglobin; FPG - fasting blood glucose; PPPG - postprandial glucose. The above analysis was performed on the modified intention to treat population which comprised patients who had completed the study up to at least week 12 without any protocol violation.

Table 3: Mean reduction in glycemic parameters compared to baseline (after 6 month)

\begin{tabular}{|l|c|c|c|c|}
\hline Category & FPG(mg/dL) & $\begin{array}{c}\text { PPPG } \\
(\mathbf{m g} / \mathbf{d L})\end{array}$ & $\begin{array}{c}\text { HbA1c } \\
(\%)\end{array}$ & $\begin{array}{c}\text { \% of patients } \\
\text { achieved, HbA1c } \\
\leq 6 \%\end{array}$ \\
\hline $\begin{array}{l}\mathrm{HCQ}+\mathrm{Met}+\mathrm{Glime} \\
(\mathrm{n}=50)\end{array}$ & $40.26 \pm 24.61$ & $89.04 \pm 36.82$ & $1.3 \pm 0.5$ & $29 \%$ \\
\hline $\begin{array}{l}\text { Vilda + Met + Glme } \\
(\mathrm{n}=50)\end{array}$ & $29.84 \pm 18.74$ & $73.94 \pm 26.85$ & $1.1 \pm 0.5$ & $11 \%$ \\
\hline
\end{tabular}

Note: Values are presented as mean \pm standard deviation otherwise mentioned.

$P$-value $<0.0001$ for all glycemic parameters in all subgroups

\section{Change of serum creatinine \& SGPT levels in the study}

There was no significance difference in serum creatinine and SGPT level for the follow-up of 6 months therapy with both the combinations, i.e.; hydroxychloroquine combinations and vildagliptin combinations (Table 4). There was no incidence of renal and hepatic toxicity with any combination drugs. 
Table 4: Distribution of Serum Creatinine\& SGPT levels in the study

\begin{tabular}{|l|c|c|c|c|}
\hline \multirow{2}{*}{ Characteristics } & HCQ + Met + SU & $\mathbf{N = 5 0}$ & Vilda + Met + SU & N=50 \\
\cline { 2 - 5 } & Before Treatment & $\begin{array}{c}\text { After } \\
\text { Treatment }\end{array}$ & Before Treatment & $\begin{array}{c}\text { After } \\
\text { Treatment }\end{array}$ \\
\hline Serum Creatinine & $0.83 \pm 0.34$ & $0.83 \pm 0.34$ & $0.82 \pm 0.31$ & $0.82 \pm 0.31$ \\
\hline SGPT & $28.68 \pm 5.59$ & $28.76 \pm 6.12$ & $28.36 \pm 5.32$ & $30.19 \pm 5.61$ \\
\hline
\end{tabular}

At 24th week eye scanning was done. Eye checkup done to evaluate corrective lenses, it has been found that in all patients $(n=100)$ pupils are equal

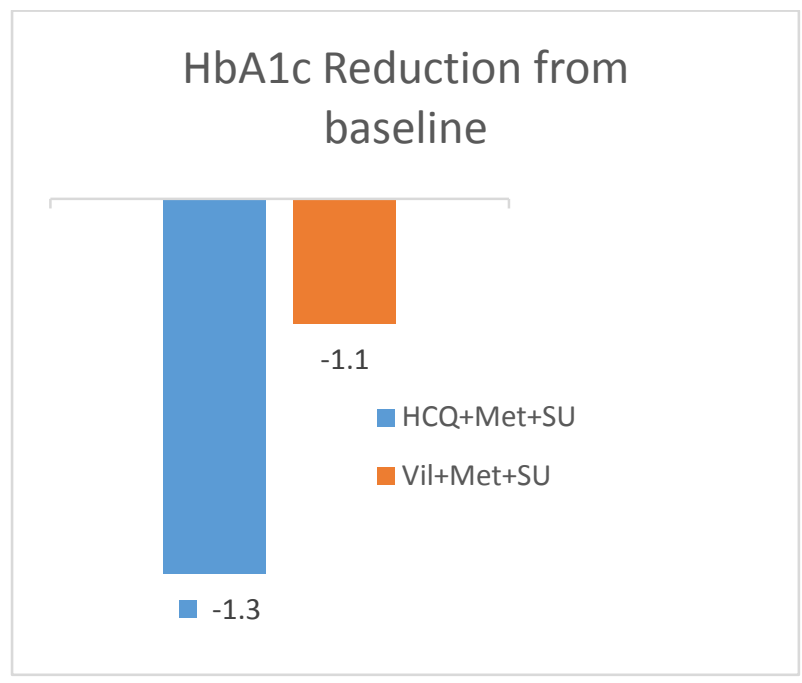

and reactive to light and accommodation, Fundi were clear and no arteriovenous nicking, no retinopathy was observed.

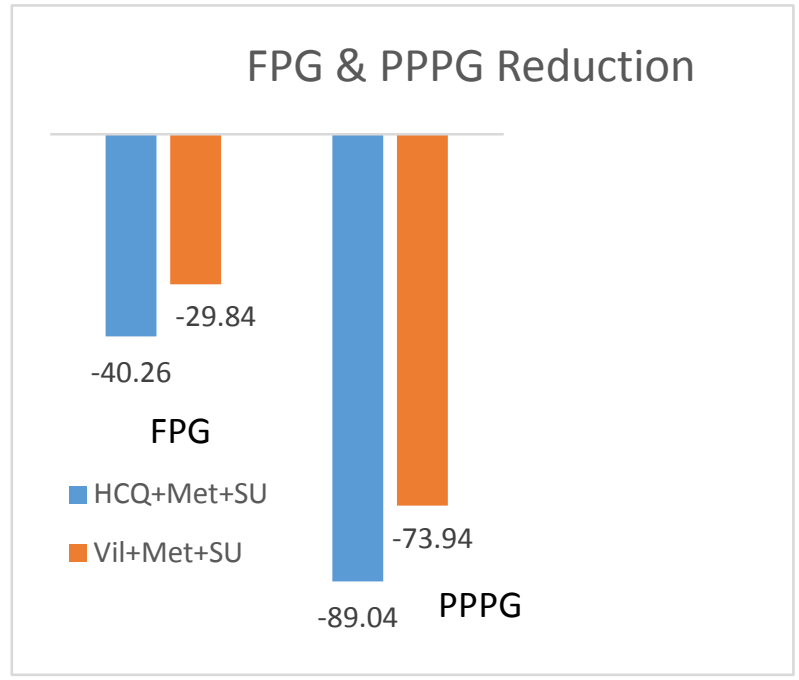

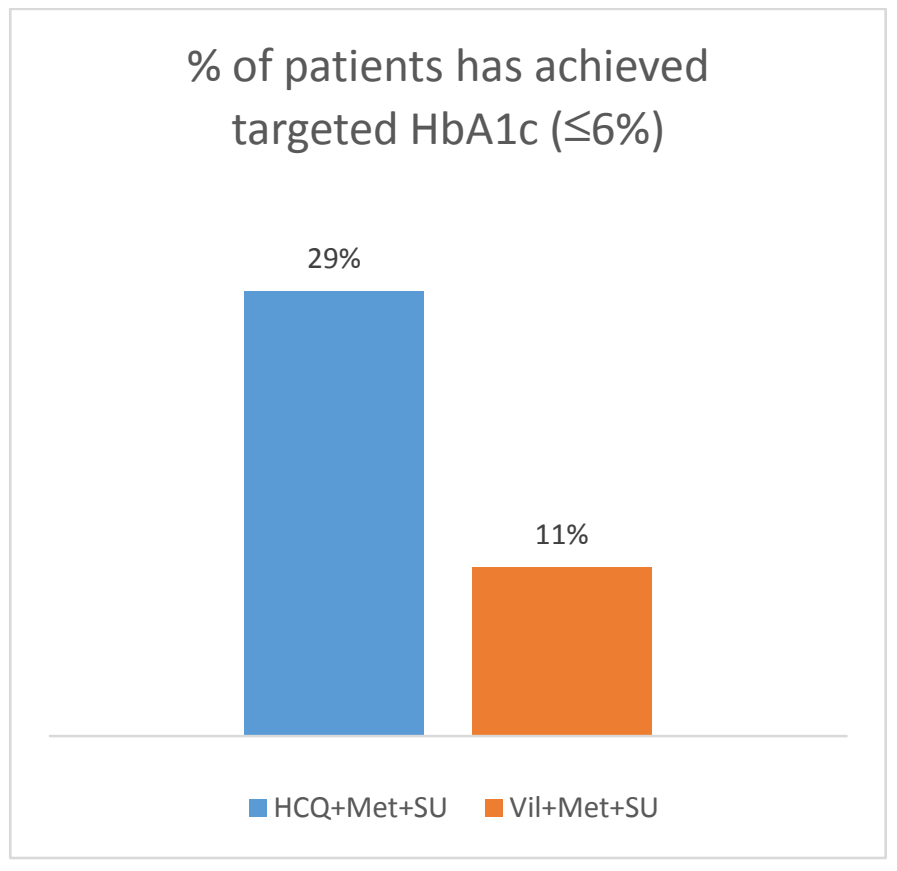

\section{Discussion}

International Diabetes Federation (IDF) and the American Association of Clinical Endocrinologists (AACE), suggest that an $\mathrm{HbA} 1 \mathrm{c} \leq 6.5 \%$ is the appropriate target for patients with type 2 diabetes and reduces the risk for micro vascular events ${ }^{9}$.

Defect in insulin clearance is an integral part of pathogenesis of type 2 diabetes mellitus ${ }^{10}$. Subjects with insulin resistance as well as diabetic 
patients exhibit an increased rate of intercellular insulin degradation ${ }^{11}$.

It has been proposed that the dissociation of insulin from its receptor appears to be the rate limiting step in the degradation process of the hormone. Scientific evidence suggest that, HCQ affects the insulin metabolism. Direct interaction of HCQ with the insulin receptor reduces the rate of dissociation of insulin from its receptor. It has been postulated that, this may increase the biological half-life of the receptor insulin complex and consequently prolong the action of insulin ${ }^{12}$. Emami $\mathrm{J}$ et $\mathrm{al}^{13}$ demonstrated that HCQ reduces the insulin clearance and subsequently lowers glucose levels in the treated subjects. Occurrence of insulin resistance is one principal aspect of metabolic syndrome. The degree of improvement in insulin sensitivity may translate into better glycemic control.

To explore the mechanism of HCQ's action on glucose metabolism, Wasko $\mathrm{M}$ et $\mathrm{al}^{14}$ conducted a randomised clinical trial of 13 weeks of treatment with HCQ vs placebo in non-diabetic adults. In non-diabetic individuals, HCQ treatment improved both insulin sensitivity and beta cell function. Significant improvement in insulin sensitivity occurred with HCQ $(20.0 \%)$ given 400 $\mathrm{mg}$ daily but not placebo $(-18.4 \%)$ with a difference of $38.3 \%$ between the two groups. A significant improvement in $\beta$-cell function with HCQ (45.4\%) was observed as compared to placebo $(-19.7 \%)$ with $65 \%$ inter group difference. Significant increase in plasma adiponectin level was also observed after HCQ treatment $(18.7 \%)$ but not after placebo $(0.7 \%)$. By increasing both low and high molecular weight adiponectin levels, HCQ may enhance the positive metabolic effects at the peripheral sites and also in the pancreas. HCQ had an effect on fasting glucose concentration, indicating that the combined changes in insulin sensitivity and beta cell function were biologically relevant.

There was no significant change in body weight or BMI of patients at the end of the study. The potential of weight gain with sulfonylureas may be neutralized by the weight loss properties of metformin and hydroxychloroquine. This finding was in accordance with the previous study conducted by Parekh et al ${ }^{15}$.

The result of this study was also in accordance with study conducted by Jagnani VK, et al, shows a statistically significant improvement in mean HbA1c, FPG, and PPPG with hydroxychloroquine combination therapy as compared to teneligliptin combination therapy on Type 2 Diabetes Mellitus unresponsive to metformin and sulfonylurea (SU) ${ }^{16}$.In our observation trial, $29 \%$ of patients has achieved targeted HbAlc $\leq 6$ with hydroxychloroquine combination where as it was only $11 \%$ with vildagliptin based regimen.

The results pointed out that all the group of patients showed an improvement in their glycemic parameters such as FPG, PPPG, and HbA1c during the study period and from the group comparison study it was observed that the patients receiving combination therapy of hydroxychloroquine have better glycaemic control than combination therapy of vildagliptin.

Taken together, these data showed that the addition of hydroxychloroquine $400 \mathrm{mg}$ could help lower the levels of HbA1c and blood glucose in patients with type 2 diabetes who were inadequately controlled with combination of metformin and sulfonylurea.

This study has certain limitations, because of the open-label design of the study, the possibility of bias cannot be ruled out. Small sample size is another limitation of this study. Information related to diet and lifestyle modification and information regarding dosing pattern of concomitant medication was not analysed. Data were collected only for duration of 6 months, so there are limitations in commenting on durability of the treatment. To address the shortcomings of the present study long term studies with more number of patients is warranted.

\section{Conclusion}

This study showed that hydroxychloroquine 400 $\mathrm{mg}$ can be an effective alternative to DPP-4 
inhibitor like vildagliptin for add on therapy to the patients who are inadequately controlled with metformin and glimepiride combination therapy.

\section{Funding}

The authors report no conflicts of interest in this work. No funding sources.

\section{References}

1. Abdulfatai B. Olokoba, Olusegun A. Obateru, Lateefat B. Olokoba. Type 2 Diabetes Mellitus: A Review of Current Trends. Oman Medical Journal (2012) ; 27: 269-273.

2. Chen, L.,Magliano, D. J., and Zimmet, P. $\mathrm{Z}$. The worldwide epidemiology of type 2 diabetes mellitus-present and future perspectives. Nature Reviews Endocrinology, 2012; 8(4): 228-236.

3. Ahmed AM. History of diabetes mellitus. Saudi Med J 2002 Apr; 23(4):373-378.

4. Hage MP, Al-Badri MR, Azar ST. A favorable effect of hydroxychloroquine on glucose and lipid metabolism beyond its anti-inflammatory role. Therapeutic advances in endocrinology and metabolism. 2014 Aug 1;5(4):77-85.

5. Quatraro A., Consoli G., Magno M., Caretta F., Nardozza A., Ceriello A., et al. (1990)Hydroxychloroquine in decompensated, treatment-refractory noninsulin-dependent diabetes mellitus.a new job for an old drug?Ann Intern Med 112: 678-681.

6. Wasko MC, Hubert HB, Lingala VB, Elliott JR, Luggen ME, Fries JF, Ward MM. Hydroxychloroquine and risk of diabetes in patients with rheumatoid arthritis. Jama. 2007 Jul 11;298(2):187-93.

7. Mudaliar S. New frontiers in the management of type 2 diabetes. Indian $\mathrm{J}$ Med Res. 2007;125: 275-96.
8. Lebovitz HE. Insulin resistance: definition and consequences. ExpClinEndocrinol Diabetes. 2001; 109 (2): 135-148.

9. Nathan DM, Buse JB, Davidson MB, Heine RJ, Holman RR, Sherwin R, et al. Management of hyperglycemia in type 2 diabetes: a consensus algorithm for the initiation and adjustment of therapy: a consensus statement from the ADA and the EAS. Diabetes Care. 2006;29(8):196372.

10. Duckworth WC et al. Endocr Rev. 1998 Oct;19(5):608-24

11. Farris $W$ et al. ProcNatlAcadSci USA. 2003 Apr 1; 100(7):4162-7

12. Iwamoto Y et al. Eur J Pharmacol. 2001 Oct $12 ; 428(3): 381-8$.

13. Emami J et al. Can J PhysiolPharmacol. 1999 Feb; 77(2): 118-23.

14. Wasko MC, McClure CK, Kelsey SF, Huber K, Orchard T, Toledo FG. Antidiabetogenic effects of hydroxychloroquine on insulin sensitivity and beta cell function: a randomised trial. Diabetologia. 2015 Oct;58(10):2336-43. doi: 10.1007/s00125-015-3689-2. Epub 2015 Jul 22.

15. Pareek A, Chandurkar N, Thomas $\mathrm{N}$ et al. Efficacy and safety of hydroxychloroquine in the treatment of type 2 diabetes mellitus: a double blind, randomized comparison with pioglitazone. Curr Med Res Opin 2014; 30: 1257-1266.

16. Jagnani VK, Bhattacharya NR, Satpathy SC, Hasda GC, Chakraborty S (2017) Effect of Hydroxychloroquine on Type 2 Diabetes Mellitus Unresponsive to More Than Two Oral Antidiabetic Agents.J Diabetes Metab 8: 771. 